\title{
PROPOSAL OF A SCALE OF TREATMENT NEEDS IN DENTISTRY FOR THE EXPEDITIONARY CORPS OF THE POLISH ARMED FORCES
}

\author{
Łukasz E. Ulański, Marcin Kozakiewicz \\ Department of Maxillofacial Surgery, Medical University of Lodz, Poland
}

\begin{abstract}
InTroduction: The involvement of Polish soldiers in establishing peace in the world has resulted in the high regard for the Polish army in the eyes of the allied forces. However, there are cases when people who have been incorrectly classified with regard to oral health reach the theater of operations.

Овјестіves: The objective of the study is the introduction of the Scale of Treatment Needs (STN).

MATERIAL AND METHODs: 384 soldiers divided into two groups were included in the study. The first group consisted of soldiers stationed in Afghanistan (196 people) and the second one was stationed in Poland (188 people). A basic dental examination was conducted among the members of both groups.

RESULTS: The STANAG 2466 indicator assigned 84 (42.86\%) of the soldiers stationed in Afghanistan and 127 (67.55\%) of those serving in Poland to groups 3 and 4. Those soldiers should not have been sent on military missions. The DMFT index (Decayed, Missing and Filled Teeth), on the other hand, was 14.96 for the first group and 11.29 for the control group. The resulting treatment indicator for the group on the mission was 0.81 and 0.54 for the one stationed in Poland. The Scale of Treatment Needs proposed by the authors confirms former results. ConcLusions: The Scale of Treatment Needs is a useful diagnostic tool which additionally indicates the treatment direction for each soldier.
\end{abstract}

KEY WORDS: military personnel, stomatognathic diseases, Afghanistan, oral health, oral hygiene.

J Stoma 2018; 71, 5: 412-419

DOI: https://doi.org/10.5114/jos.2018.84766

\section{INTRODUCTION}

For years Polish soldiers have been taking part in international missions. Iraq, Chad, and Afghanistan are only some of the places where they served or still serve. This is the reason for the need of an efficient dental classification of the patients who seek to be sent on a mission as well as after its termination. In order to ensure the participants of the expedition appropriate conditions of existence, providing proper medical care before and during the stay is crucial. Polish soldiers remained under the care of the dental practice that belongs to the Polish Field Hospital also during their deployment of at least 6 months. Quite often, soldiers who were already in the military operations zone visited the dental office first in order to have their teeth treated. They had numerous dental problems. This was caused by the lack of accurate classification and diligence during the tests performed by the medical committee $[1,2]$.

Soldiers seeking to be sent on a mission have mentioned very alarming issues. Namely, it was a rather common situation that people who wished to be deployed on

\section{JOURNAL OF STOMATOLOGY CZASOPISMO STOMATOLOGICZNE


a mission to Afghanistan gave personal data of another person in an attempt to pass the medical verification successfully. All too often soldiers with dental problems were giving their IDs to those with healthy teeth $[1,2]$. Healthy patients who did not have inflammation within the stomatognathic system posed as people suffering from dental issues in order to be qualified for a mission.

The verification performed by the certifying dentists was not reliable either. Very often no basic dental examination was performed when the ability to go on a mission outside the country was decided. Some dentists would sign the documents without performing a dental examination $[1,2]$. In recent years, decisions were made without taking the panoramic X-ray. Now, however, such diagnostics is performed when deciding on the capacity to serve outside the country.

Soldiers mentioned the problem with the access to dental care in their respective military bases in the country. The entire military medical care suffers from a lack of qualified dental personnel, i.e. officers who would be able to provide assistance in the military bases. A mission candidate is often given a heavy load of all kinds of pre-mission training, which is why there is no time left for dental treatment. This was also noted by Richardson when referring to the British army [3]. We can, therefore, suppose that soldiers who seek to go on military missions have trouble undergoing dental treatment due to the overload of general military activities.

Dental offices in military bases do not operate properly either. Such places are often closed due to lack of qualified staff or due to lack of legal grounds for such facilities to exist. Currently, there are only a few military bases with dental offices, and those are special and aviation units where such care is provided.

Oral health of the soldiers has an effect on the performed functions and their availability. The main infectious diseases caused by oral diseases are tooth decay and inflammation of periapical tissues related to it. This type of condition is represented by periodontal diseases to a much lesser degree. This was confirmed by Korzeniewski and Krall [1], according to whom the most common reason for the soldiers to report to dental offices was tooth decay, which represented $60.4 \%$ of all cases, whereas pulp inflammation constituted $16.5 \%$ of the cases. The percentage of interventions caused by periodontal diseases was $13.8 \%$ of the cases. During a 6-month observation period the authors found that $30.6 \%$ of Polish soldiers required dental interventions. The studies conducted by Gunepin et al., who researched the incidence among French soldiers, confirm that [4]. Namely, they concluded that the reason for the majority of cases of dental interventions was tooth decay at $43 \%$. The second largest group of illnesses comprised cases of pulp diseases, which constituted $18 \%$ of all cases, followed by periodontal diseases constituting $4 \%$ of the reported problems treated at the dental office on a mission. Dental problems among the soldiers stationed in southern provinces have also been noted in the Royal Thai Army. The studies included a group of 2884 people from April 2011 to March 2013. The survey showed that $32.4 \%$ of the respondents experienced a toothache or hypersensitivity. $21.5 \%$ of the population, on the other hand, had tooth decay of various intensity [5]. The research conducted by Brajdić et al. in the Croatian army with the participation of 400 soldiers (200 recruits and 200 soldiers in active service) demonstrates a poor state of oral health among newly recruited soldiers. According to the observations of Croatian researchers $66 \%$ of the studied population of soldiers requires immediate dental intervention, whereas only $18 \%$ of the participants required no dental intervention in a period of 12 months and $15.5 \%$ of the studied soldiers required dental treatment in the period of 1 year. Mouth condition improves together with the time spent in the army. It results from the fact that dental treatment is refunded in Croatian army military bases [6].

\section{OBJECTIVES}

The objective of the study is to present our own Scale of Treatment Needs in the area of dentistry for the needs of the Expeditionary Corps of the Polish Military Forces. Having such a scale, a doctor who works on the military committee can clearly indicate if a given mission candidate qualifies for this kind of service or not.

\section{MATERIAL AND METHODS}

Living and social conditions on a mission to Afghanistan were satisfactory. The Polish Field Hospital located at the FOB (Forward Operation Base) base Ghazni was a part of the Polish Military Contingent sent to Afghanistan. Polish and American soldiers were stationed in that base [7]. The entire complex was built out of containers. The base had a dental office which was run by a dentist - office manager, and a dental assistant. The intermediate staff of the dental office consisted of a random nurse or a trained dental assistant. It was the hospital commanding officer who decided on the recruitment of the intermediate staff, not the dentist himself. Due to that, such a nurse had to be trained in dental procedures at the beginning of the mission. It was easier for the dentists who had a trained dental assistant assigned on previous shifts. One shift lasted about 6 months; however, due to personnel shortages, a doctor could go on a mission for 3 months. The dental office was equipped with a 20 -ft container, radiovisiography (RVG) device, autoclave, and a field dental unit. Unfortunately, however, this container was not suitable for dental practice. Namely, it had no running water installation, no drainage system, and no integrated compressor installed. This is why the used tools had to be washed in general hospital bathrooms. 


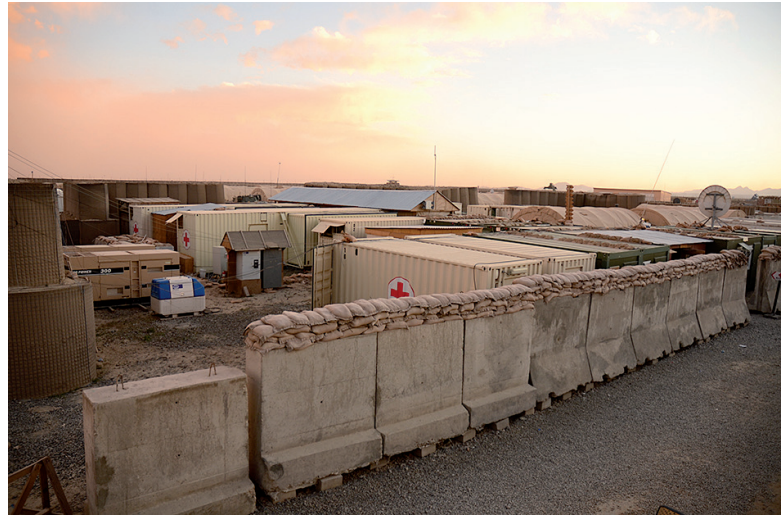

FIGURE 1. Container hospital in FOB Ghazni

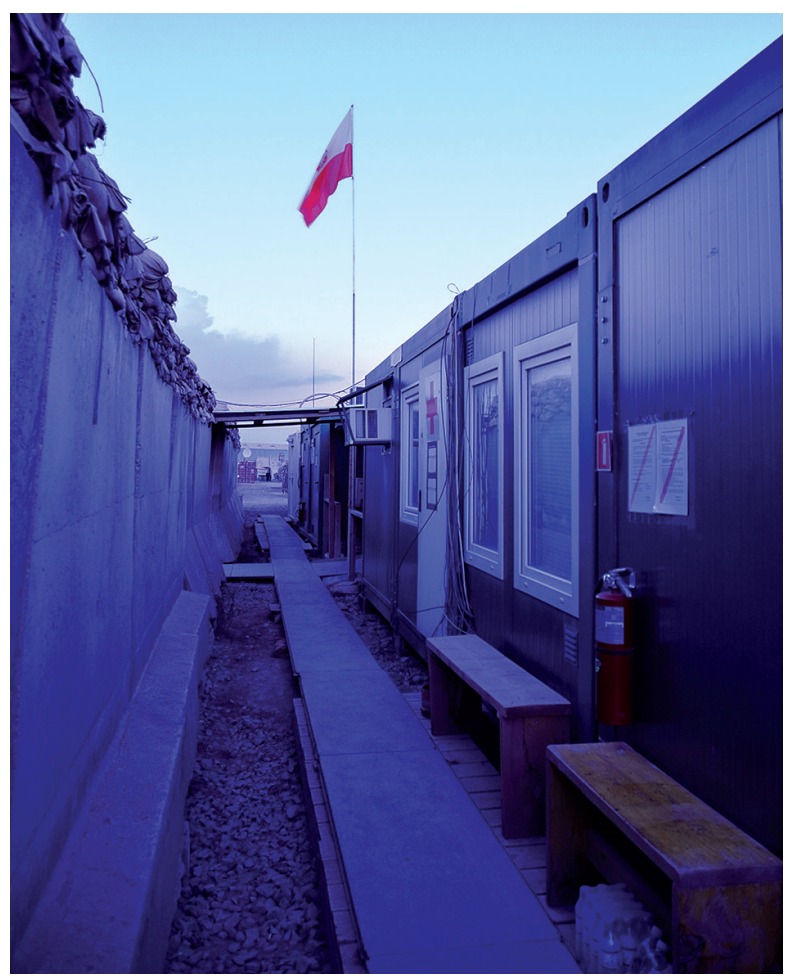

FIGURE 2. Dental practice container

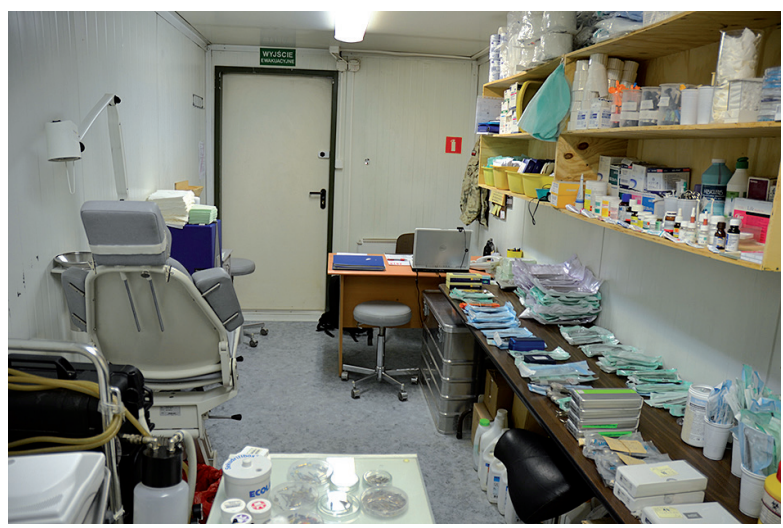

FIGURE 3. Interior of the dental practice container
In reality, the dental practice room was just a housing container adapted for that function (Figure 1) $[1,8]$.

The safety on a mission was not complete. There were many battle alarms which interrupted the dentist's work. In such situations, the dentist and the patient had to go to the shelter and wait for the missile assault or gunfire to cease (Figures 2 and 3) [1,2].

Based on the observed treatment needs and possibilities of their provision, a Scale of Treatment Needs (STN) has been developed. Values from 0 to 7 have ascending treatment needs assigned to them. The proposed scale is illustrated in Table 1.

Values from 0 to 3 represent the needs that can be secured in conditions of an international mission. Values from 4 to 6 require the collaboration of a dental laboratory, whereas a value of 7 requires performing treatments in the area of dental surgery. Treatment procedures that correspond to those values constitute a significant obstacle in the provision of dental care during an international mission or they can even be impossible to perform. While values from 4 to 6 that are untreated may only become a complication for soldiers due to physical debilitation and decline in physical appearance, soldiers assigned to point 7 should not be a part of expeditionary corps. Dental treatment needs in the area of surgery can exclude a soldier from active service and cause severe complications. Apart from that, they are always an obstacle for a dentist working in a mission base.

Another scale analyzed by the authors was the STANAG 2466 scale introduced by NATO forces. This scale is based on the determination of the dental condition of the personnel seeking to participate in a military mission [1, 4, 9-13]. It proposes a classification of soldiers into 4 groups:

1. People with no dental problems.

2. Soldiers with minor dental defects that do not require intervention for a period of 12 months.

3. People with significant dental problems that require dental assistance within a period of 6 months.

4. Soldiers who require urgent dental intervention.

People assigned to groups 3 and 4 should not be sent on international missions.

Only soldiers classified as belonging to groups 1 and 2 may be admitted for participation in military contingents.

Despite the fact that this division is not perfect as it does not reflect the loss of masticatory function, it has become a standard among the coalition forces.

In the Polish Armed Forces, the loss of masticatory function has been taken into account for a significant time. The principal indicator in such cases is the number of lost teeth. There are certain rules as to the determination of dental losses. Namely, all functional prosthetic restorations are regarded as a restored loss of teeth and included in the number of teeth as natural teeth without loss of masticatory function. As a rule, third mo- 
TABLE 1. Treatment needs and how they are secured

Scale of Treatment Needs (STN)

Securing conditions

0 - no treatment needs

1- scaling, preventive dental care

2 - conservative treatment

3 - scaling, conservative treatment

4 - prosthetics

5 - scaling, prosthetics

6 - scaling, conservative treatment, prosthetics or conservative treatment, prosthetics

7 - dental surgery and other dental procedures

Needs secured on an international mission

Needs secured with the collaboration of a dental laboratory

Surgical needs secured in the country

TABLE 2. Percentage values of loss of masticatory function in reference to particular teeth

\begin{tabular}{|l|c|}
\hline Tooth & $\begin{array}{c}\text { Percentage values of loss of masticatory function } \\
\text { (\%) }\end{array}$ \\
\hline Medial incisor & 4 \\
\hline Lateral incisor & 3 \\
\hline Canine & 6 \\
\hline First premolar & 7 \\
\hline Second premolar & 7 \\
\hline First molar & 11 \\
\hline Second molar & 12 \\
\hline Third molar & 0 \\
\hline
\end{tabular}

lar teeth are not considered functional teeth. However, if the tooth is moved to the position of the first or second molar, filling a gap that had been there, then the tooth is regarded as a fully functional tooth that restores the masticatory function. Those data are illustrated in Table 2.

The loss of masticatory function is calculated by summing the percentage values of all the missing teeth. Soldiers who wish to participate in military missions cannot exceed the value of $67 \%$ of the loss of masticatory function [14].

The scale was tested on 384 patients who qualified to participate in a stabilization mission in Afghanistan. They were divided into two groups of patients. The first group included soldiers who were in a theater of operations (196 people), whereas the second group (188 people) included soldiers stationed in Poland, who were in the process of preparations for a mission. The second group was a control group. Statistical tests were performed using ANOVA variance analysis. The tests were based on the analysis of dental diagrams included in the consultation records books of the dental office in the country and in Afghanistan. They were the basis for the calculation of loss of masticatory function of particular soldiers.

The DMFT index (Decayed, Missing, and Filled Teeth) and the resulting treatment and OHI-S (Oral
Hygiene Index - Simple) indices were used for analysis. Classification established by NATO according to STANAG 2466 standards has also been analyzed [9].

\section{RESULTS}

Dentists' working hours were set by the field hospital's commanding officer. The doctor should attend patients with pain within the established hours. In practice, however, patients with all kinds of problems would come to see the dentist. Apart from Polish soldiers, American soldiers as well as civilians working for the military forces would sometimes come to the dental office. Afghans would also attend. They were treated following express instructions from the Polish command. Except for patients with pain, the practice often received soldiers with general dental problems, such as loss of fillings, scaling, and broken or decemented permanent prosthetic restoration. This is the reason why, except for surgical procedures, such as extraction, the doctor performed restoration using composite materials, endodontic treatment, scaling, and minor prosthetic procedures, such as cementing a prosthetic piece. Personnel of the field hospital does not include a dental technician, which is why it is understandable that full prosthetic procedures or repairs of orthodontic braces cannot be performed.

Average age of the examined patients was 36.14 \pm 6.4 for soldiers stationed in Afghanistan and 25.88 \pm 7.7 for those stationed in Poland. The youngest participant was 25 years old, whereas the oldest was 57 years old. Inside the country, the disparity was much larger, where the youngest patient was 18 and oldest was 56 years old.

In the group serving in Afghanistan, the average value of the $\mathrm{D}$ index was 1.63 (SD - 1.91; min - 0; $\max -12.0$; median -1.0$)$. The average value of the F index was 3.11 ( $\mathrm{SD}-2.8$; $\min -0$; $\max -16.0$; median - 3.0). The average value of the $\mathrm{M}$ index was 10.21 ( $\mathrm{SD}-2.80$; min -0 ; $\max -27.0$; median - 10). This led to the calculation of the DMFT index, which equaled 14.96 \pm 5.6. The treatment indicator resulting from the above data 
TABLE 3. Interpretation of results of the OHI-S scale according to Green and Vermilion

\begin{tabular}{|l|c|}
\hline OHI-S Classification & $\begin{array}{r}\text { Interpretation of results according to } \\
\text { Green and Vermilion } \\
\text { Very good hygiene }\end{array}$ \\
\hline 0.0 & Good hygiene \\
\hline $0.1-1.2$ & Sufficient hygiene \\
\hline $3.3-3.0$ & Poor hygiene \\
\hline
\end{tabular}

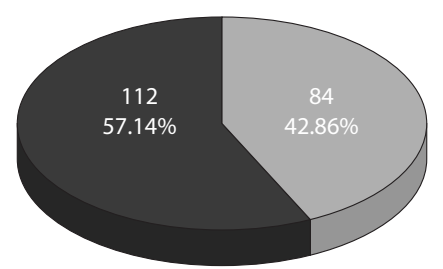

— People fit for service on international missions

$\square$ People who should not be allowed on military missions

FIGURE 4. Division of the soldiers stationed in Afghanistan into fit and unfit for service outside the country

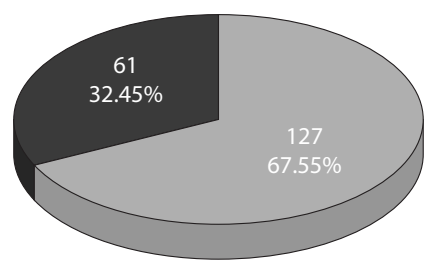

- People fit for service on international missions

$\square$ People who should not be allowed on military missions

FIGURE 5. Division of the soldiers serving in Poland into fit and unfit for service outside the country

was 0.81 . The average value of OHI-S among the soldiers was 0.97 . This means that dental hygiene was at a good level, in accordance with the result assessment proposed by Greene and Vermilion [15]. This classification is illustrated in Table 3. It should be mentioned, however, that the maximum value of the studied group was 4.34 (poor hygiene), and minimum 0.0 (very good hygiene).

For the control group of people in Poland, those values were considerably different. Namely, the average value of the $\mathrm{D}$ index was 3.71 ( $\mathrm{SD}-3.53$; $\min -0$; $\max -16.0$; median -3.0 ). The average value of the F index was 2.0 ( $\mathrm{SD}-2.0$; $\min -0$; $\max -14$; median - 2.0). The average value of the $M$ index was 5.55 (SD - 5.31; min - 0; $\max -23$; median - 4.0). This led to the calculation of the DMFT index, which equaled 1.29 \pm 5.38 . The treatment indicator resulting from the above data was $0.54 \pm 0.38$. The average value of OHI-S among the soldiers was $1.39 \pm 1.13$. This means that dental hygiene was on a sufficient level. The maximum value of the studied group was 4.83 (poor hygiene) and minimum 0.0 (very good hygiene).

Average loss of masticatory function of an average soldier stationed in Afghanistan was 16.37\%. However, there was one soldier whose loss of masticatory function reached $82 \%$. Due to the above, he should not participate in a military mission. Additionally, it was observed that the number of people who should go on missions due to the loss of masticatory function exceeding the statutory $67 \%$ was 3 .

In the control group (soldiers serving in Poland), the average loss of masticatory function was $13.8 \%$. The maximum degree of the loss of masticatory function in the case of one soldier was $74 \%$. Due to the above, this soldier should not have been enlisted in the army. In this group it was also observed that the number of people who should not be in the Polish Army due to the loss of masticatory function exceeding the statutory $67 \%$ was 2. The authors have also made an attempt to classify Polish soldiers according to the STANAG 2466 standard. The results are illustrated in Table 4.

The above data demonstrate that in the group of people sent on a mission, 84 people $(42.86 \%)$ represented two last groups according to the STANAG 2466 classification. Due to that fact, those patients should not have been allowed to go on military missions. On the other hand, 112 candidates (57.14\%) were included in health groups 1 and 2. Those people could be allowed to serve outside the country. The data are illustrated in Figure 4 in the form of a pie chart.

TABLE 4. Division of soldiers according to STANAG 2466

\begin{tabular}{|c|c|c|c|c|}
\hline $\begin{array}{l}\text { Group according } \\
\text { to STANAG } 2466\end{array}$ & $\begin{array}{l}\text { Number of soldiers } \\
\text { stationed in Poland } \\
\text { (control) }\end{array}$ & $\begin{array}{l}\text { Percentage value } \\
\text { of the soldiers stationed } \\
\text { in Poland (\%) }\end{array}$ & $\begin{array}{l}\text { Number of soldiers } \\
\text { stationed in Afghanistan }\end{array}$ & $\begin{array}{l}\text { Percentage value } \\
\text { of the soldiers stationed } \\
\text { in Afghanistan (\%) }\end{array}$ \\
\hline Group 1 & 21 people & 11.17 & 46 people & 23.47 \\
\hline Group 2 & 40 people & 21.28 & 66 people & 33.67 \\
\hline Group 3 & 25 people & 13.30 & 49 people & 25.00 \\
\hline Group 4 & 102 people & 54.25 & 35 people & 17.86 \\
\hline Total & 188 people & 100.00 & 196 people & 100.00 \\
\hline
\end{tabular}




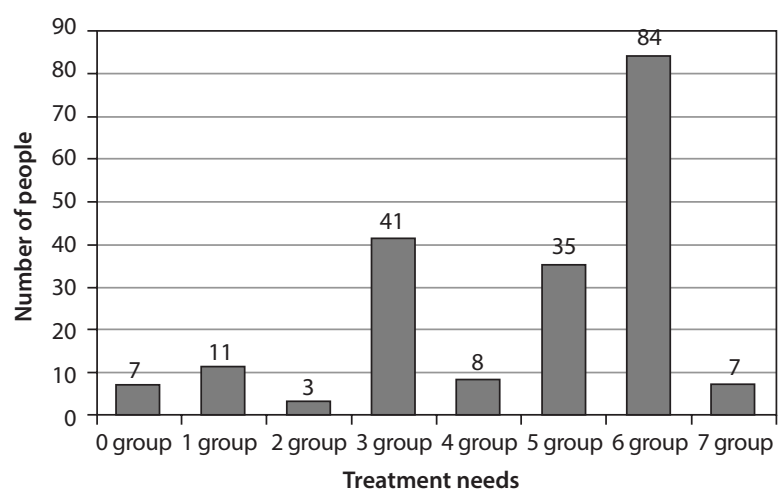

FIGURE 6. Graph illustrating treatment needs in the population of 196 soldiers serving in Afghanistan

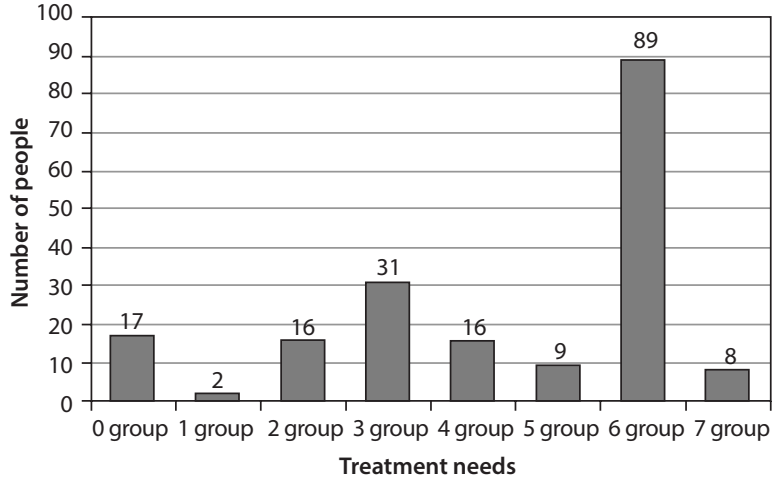

FIGURE 7. Graph illustrating treatment needs in the population of 196 soldiers serving in Poland

TABLE 5. Division of the Scale of Treatment Needs (STN) of particular soldiers serving in Afghanistan

\begin{tabular}{|c|c|c|}
\hline Group & Number of people & Percentage value (\%) \\
\hline 0 - no treatment needs & 7 & 3.57 \\
\hline 1 - scaling, preventive dental care & 11 & 5.61 \\
\hline 2 - conservative treatment & 3 & 1.53 \\
\hline 3 - scaling, conservative treatment & 41 & 20.92 \\
\hline 4 - prosthetics & 8 & 4.08 \\
\hline 5 - scaling, prosthetics & 35 & 17.86 \\
\hline 6 - scaling, conservative treatment, prosthetics or conservative treatment, prosthetics & 84 & 42.86 \\
\hline 7 - dental surgery and other dental procedures & 7 & 3.57 \\
\hline Total & 196 & 100.00 \\
\hline
\end{tabular}

In the Polish (control) group, however, it was observed that out of all the soldiers serving in Poland, $127(67.55 \%)$ people belonged to the two last categories in the classification STANAG 2466. Due to that fact, those patients should not be allowed to go on international military missions due to extensive problems of the stomatognathic system. Only 61 (32.45\%) soldiers, on the other hand, belonged to the qualifying groups 1 and 2 . Those people could be allowed to serve outside the country. The data are illustrated in Figure 5 in the form of a pie chart.

The above classification does not shed any light on the manner of supplying soldiers who are on missions or seek such endeavors. This is the reason why the authors have proposed the Scale of Treatment Needs (STN) for soldiers serving in the Polish Army. This classification is aimed at the verification of candidates for international missions and demonstrates what treatment needs can be guaranteed for the soldiers who are on missions. As mentioned above, the possibilities of treatment in a dental practice on an international mission in the Polish Field Hospital are severely limited at level 2+. There is no prosthetic laboratory or computed tomography, and the office is manned by only one dentist who often has no specialty training [8]. Due to the above, the two studied groups were classified according to the Scale of Treatment Needs (STN).

People from the group stationed in Afghanistan, who were placed in groups $0-3$, constituted 62 of all the examined patients, which represented only $31.63 \%$ all the entire group of soldiers sent to Afghanistan. Therefore, those people could participate in an international mission as these soldiers could be ensured treatment by a Polish dental practice in field conditions. Soldiers assigned to groups $4-6$, on the other hand, constituted 127 people of the entire examined group of soldiers (64.80\%). Those people did not have guaranteed prosthetic care due to the lack of a technical dental laboratory on missions. This is the group that should not have been allowed to participate in an international mission. Patients assigned to group 7, however, with complex surgical needs, should never have been placed in a theater of operations as it is related to danger for their health and high costs of evacuation by air to the Dental Clinic in Bagram base. This group included 7 soldiers, which represented $3.75 \%$ of the studied population. The above groups are illustrated in Figure 6 and Table 5.

People from the group stationed in Poland, who were placed in groups $0-3$, constituted 66 of all the examined patients, which represented only $35.10 \%$ of the entire 
TABLE 6. Division of the Scale of Treatment Needs (STN) of particular soldiers serving in Poland

\begin{tabular}{|l|c|c|}
\hline Group & Number of people \\
\hline $0-$ no treatment needs & 17 & 2 \\
\hline $1-$ scaling, preventive dental care & 16 & 1.04 \\
\hline $2-$ conservative treatment & 31 & 16.51 \\
\hline $3-$ scaling, conservative treatment & 16 & 9.49 \\
\hline $4-$ prosthetics & 8.51 \\
\hline $5-$ scaling, prosthetics & 89 & 4.79 \\
\hline $6-$ scaling, conservative treatment, prosthetics or conservative treatment, prosthetics & 8 & 47.34 \\
\hline $7-$ dental surgery and other dental procedures & 188 & 100.00 \\
\hline Total & & 4.26 \\
\hline
\end{tabular}

group of soldiers sent to Afghanistan. Therefore, those people could participate in an international mission as these soldiers could be ensured treatment by a Polish dental practice in field conditions. Soldiers assigned to groups 4-6, on the other hand, constituted 114 people of the entire examined group of soldiers (60.64\%). Those people should not be qualified to go on international missions due to the lack of a technical dental laboratory there. All the prosthetic work should be performed in the country in home bases or in military health care centers. Patients assigned to group 7, however, with complex surgical needs, should never have been placed in a theater of operations as it is related to danger for their life and health. This group included 8 soldiers, which represented $4.26 \%$ of the studied population.

The above groups are illustrated in Figure 7 and Table 6 .

\section{DISCUSSION AND CONCLUSIONS}

The presented Scale of Treatment Needs (STN) is strongly connected to the indices DMFT, OHI-S, and STANAG from the statistical point of view. This determines its value and predictability of its indications as a single index regarding the condition of the oral cavity and the needs for its treatment.

Soldiers whose results assign them to groups above 3 should not be a part of the international corps. It would be best if no people with the STN above 1 were to become a part of it. In reality, in the theater of operations there were representatives of all the above-presented groups. This carries the risk of a lack of possibility to provide help in complicated dental cases as well as the increase of costs of treatment or evacuation of such people.

Military decision-making and treatment in the country should be closely related and have a significant effect on the soldiers who are on missions. One institution cannot operate independently of the other. Soldiers sent abroad should be verified by an efficiently operating system of medical committees which should classify patients once they have undergone treatment in their home military bases. This entire system should operate based on a centralized computer system of soldiers' medical database. This is a dependence observed by Groves in the Canadian army [13].

Efficient dental preparation for international military missions is possible based on the presented scale of treatment needs. The scale makes it possible to avoid sending soldiers who need complex, expensive, and difficult to perform treatments in the area of military operations. The scale allows for a quick and exact determination of the kind of dental services required. Thanks to it, it is possible to define where and to what degree a soldier can receive specialized assistance. The proposed scale makes the military decision-making process easier and leads to more transparent decisions.

\section{FUNDING SOURCE}

Medical University of Lodz 503/5-061-02/503-51001-18.

\section{CONFLICT OF INTEREST}

The authors declare no potential conflicts of interest with respect to the research, authorship, and/or publication of this article.

\section{References}

1. Korzeniewski K, Krall K. Prevalence of dental disease among soldiers serving in the Polish Military Contingent in Afganistan. Lek Woj 2011; 89: 310-317.

2. Ulański $Ł$, Trykowski J. The state of oral cavity health of soldiers serving at 10 rotation in the Polish Military Contingent in Afganistan. Stomatol Współczesna 2013; 20: 8-14.

3. Richardson P. Dental morbidity in United Kingdom Armed Forces, Iraq 2003. Mil Med 2005; 170: 536-541.

4. Gunepin M, Derache F, Ausset I, et al. The rate of dental emergencies in French Armed Forces deployed to Afganistan. Mil Med 2011; 176: 828-832. 
5. Sutthavong S, Ukritchon S, Rangsin R. Oral health survey of the military personnel deployed to the southernmost provinces of Thailand. J Med Assoc Thai 2014; 97: 60-67.

6. Brajdić D, Skec V, Macan J, et al. Impact of dental emergencies on combat readiness in Croatian Army. Acta Med Croat 2006; 60: 341-345.

7. Korzeniewski K. Analysis of health risk for example peaceful mission with participation of Polish Military Contingent in Iraq and Afghanistan. Thesis on a post-doctoral degree, 2008.

8. Korzeniewski K, Pieniuta S, Nowak B, et al. Task and structure of the health service of the Polish Military Contingent in Afghanistan. Lek Woj 2011; 89: 364-375.

9. Nato Centre of Excellence for Military Medicine. Dental fitness standards for military personnel and the NATO dental fitness classification system. Nato Centre of Excellence for Military Medicine. Available at: http://www.coemed.org/images/Courses_pdf/ stanags/ds/2466_AMedP-4.4 EDA V1 E.pdf. Published October 2014. Accessed June 12, 2017.

10. Hemme C. The work of the NATO COMEDS Dental Service Expert - Panel. Med Corps Int Forum 2010; 4: 39-41.

11. Dunn W. Dental emergency rates at an expeditionary medical support facility supporting Operation Enduring Freedom. Mil Med 2004; 169: 349-353.

12. Mahoney G. The Australian experience in dental classification. Mil Med 2008; 173: 15-17.

13. Groves R. Dental fitness classification in the Canadian Forces. Mil Med 2008; 173: 18-22.

14. 3 June 2015 Regulation of the Minister of National Defense regarding the decisions on capacity or incapacity for professional military service and characteristics and procedures of military medical committees in those matters. Journal of Laws, No. 0, item 761; 2015: 1-95.

15. Greene J, Vermillion J. The simplified oral hygiene index. J Am Dent Assoc 1964; 68: 7-13. 